\title{
Association of rotating shiftwork with preterm births and low birth weight among never smoking women textile workers in China
}

\author{
Xiping Xu, Min Ding, Baoluo Li, David C Christiani
}

\begin{abstract}
1035 married women workers in three modern textile mills in Anhui, China were surveyed to investigate the association of rotating shiftwork with low birth weight and preterm birth in 1992. Information on reproductive health, occupational exposure history, and other covariates including age at pregnancy, time and duration of leave from job since pregnancy, and mill location was obtained by trained nurses with a standardised questionnaire. This analysis was limited to 845 women (887 live births), who were middle or high school graduates, never smokers, and non-alcohol drinkers. About $72 \%$ of the women worked an eight day cycle with shift changes every two days throughout pregnancy. Mean gestational age was 38.8 and 39.0 weeks for shift and regular schedule workers, respectively. Multiple linear regression was used to adjust for confounding factors including maternal age at pregnancy, order of live birth, mill location, job title, occupational exposure to dusts/gases/fumes, stress, carrying and lifting of heavy loads, working in a squat position, time and duration of leave from the job since pregnancy, and indoor coal combustion for heating. The adjusted difference in gestational age associated with rotating shifts was statistically significant $(\beta=-0.44$ (SE 0.20) weeks.) Mean birth weights were $3248 \mathrm{~g}$ and $3338 \mathrm{~g}$ for rotating shift workers and regular schedule workers respectively. The estimated effect of rotating shiftwork on birth weight was -79 (SE 42) g. When the analysis was restricted to first order live births or to production workers, the estimated effects of rotating shiftwork on both gestational age and birth weight were significant. The proportions of preterm birth $(<37$ weeks) and low birth weight $(<2500 \mathrm{~g})$, respectively, were $20 \%$ and $9 \%$ for shift workers and $15 \%$ and $6 \%$ for regular schedule workers. The adjusted odds ratio of shiftwork was 2.0 (95\% confidence interval $(95 \%$ CI $1 \cdot 1-3.4)$ for preterm birth and $2 \cdot 1(95 \%$ CI $1 \cdot 1-4 \cdot 1)$ for low birth weight. This association remained significant when the analysis was restricted to production workers or first order live births.
\end{abstract}

(Occup Environ Med 1994;51:470-474)
Shiftwork is commonly practised in both industrialised and developing countries. A shift worker is usually defined as a person who begins working at a time other than between 700 and 900 am. $^{1}$ In 1981 , about $27 \%$ of the United States workforce was in some type of shift system. ${ }^{1}$ Data available at the national level in developing countries indicate that shift workers account for at least $10 \%$ of the industrial workforce, and their numbers are gradually increasing. ${ }^{2}$ Publications on association between shiftwork and pregnancy outcomes are limited.

Birth weight and gestational age are the most important predictors for perinatal mortality. ${ }^{3}$ Several recent studies on women who gave birth at maternity or general hospitals have reported that shiftwork was associated with low birth weight or preterm birth. ${ }^{45}$ Shiftwork schedules varied greatly between industries. The information from previous studies was insufficient to characterise industries by types and distribution of shiftwork.

The present study of reproductive health collected data on a sample of 1035 married non-smoking women workers in three textile mills in Anhui, China. More than two thirds of the workers in this sample were on rotating workshifts with an eight day cycle during their pregnancy, providing an opportunity to examine effects of rotating shiftworknamely, frequent changing of the shift timeon preterm birth and birth weight.

\section{Methods}

The sampling procedure has been described in a separate report. ${ }^{6}$ Briefly, we surveyed 1035 married women workers who were employed in one of three modern textile mills (Huaibei first textile mill, Huaibei second textile mill, and Suzhou textile mill) in Anhui, China in 1992. Two of these mills, the Huaibei first textile mill and the Huaibei second textile mill, were built in 1978, and a third, the Suzhou textile mill, was built in 1984. All three mills had comparable facilities, equipment, production process, and products. Each mill ran three full shifts. Production workers were on rotating workshifts with an eight day cycle: morning shift (6 $00 \mathrm{am}-200 \mathrm{pm}$ ) for two days, evening shift (200 pm-10 $00 \mathrm{pm}$ ) for two days, night shift (10 00 pm-6 00 am) for two days, and followed by two days off. For the purpose of this study, non-rotating (day shift) workers are referred to as regular schedule workers. Most
Accepted for publication 8 March 1994. 
non-rotating workers were administrative workers whose salary and general socioeconomic class were not different from production workers.

A standardised questionnaire was used by trained nurses to obtain information on maternal reproductive history, cigarette smoking, alcohol consumption, occupational exposures, indoor air pollution, and demographic characteristics. As well as information on rotating shiftwork, the other major occupational agents collected in the survey included exposures to dusts, gases and fumes, physical activity, and position while working (for example, working in a squat position, carrying or lifting heavy loads), and psychological stress at work. If a woman reported a history of pregnancy, detailed information on pregnancy outcomes, occupational exposures during pregnancy, and the time and duration of leave from the job since pregnancy was collected.

Birth weight and gestational age were first analysed as continuous variables. Linear regression was used to assess the association of rotating shiftwork with gestational age and birth weight. The variance of ordinary least square estimates was corrected with the robust method ${ }^{7}$ because the outcomes of consecutive births given by the same mother may be correlated. Confounding factors adjusted in the regression model included mill location, maternal age at pregnancy, job title, time and duration of leave from the job since pregnancy, order of live births, exposures to dusts/gases/fumes, physical activity and position while working, stress at work, and use of coal stove for heating at home. The association of low birth weight $(<2500 \mathrm{~g})$ and preterm birth (gestational age $<37$ weeks) with rotating shiftwork was estimated by a multiple logistic regression model. The regression coefficients are estimated assuming independence among all observations. Then, robust variance estimates ${ }^{7}$ were calculated for the estimated regression coefficients to accommodate repeated measures on subjects.

\section{Results}

We used 887 live births (first order 845, second order 42) in the analyses (figure). The mothers of these babies were all middle or high school graduates, never-smokers, and non-alcohol drinkers. The means (SD) of birth weight and gestational age in this sample were 3274 (490) $\mathrm{g}$ and $38.8(2 \cdot 3)$ weeks respectively. Mean maternal age at pregnancy was $23.8(2.5)$ years.

Table 1 shows sample characteristics and percentages of rotating shift workers. About $72 \%$ of women in the three textile mills were on rotating workshifts during pregnancy. The prevalence of shiftwork was twofold higher in women with first order births than in those with second order births, and threefold higher in production workers than in other workers.

Mean gestational age was 38.8 weeks for workers reporting rotating shiftwork during pregnancy and 39.0 weeks for those reporting no such history (table 2 ). The adjusted difference in gestational age associated with rotating shifts was -0.44 (SE 0.20$)$ weeks, which was statistically significant. Mean birth

Figure 1 Description of study participants and excluded subjects.

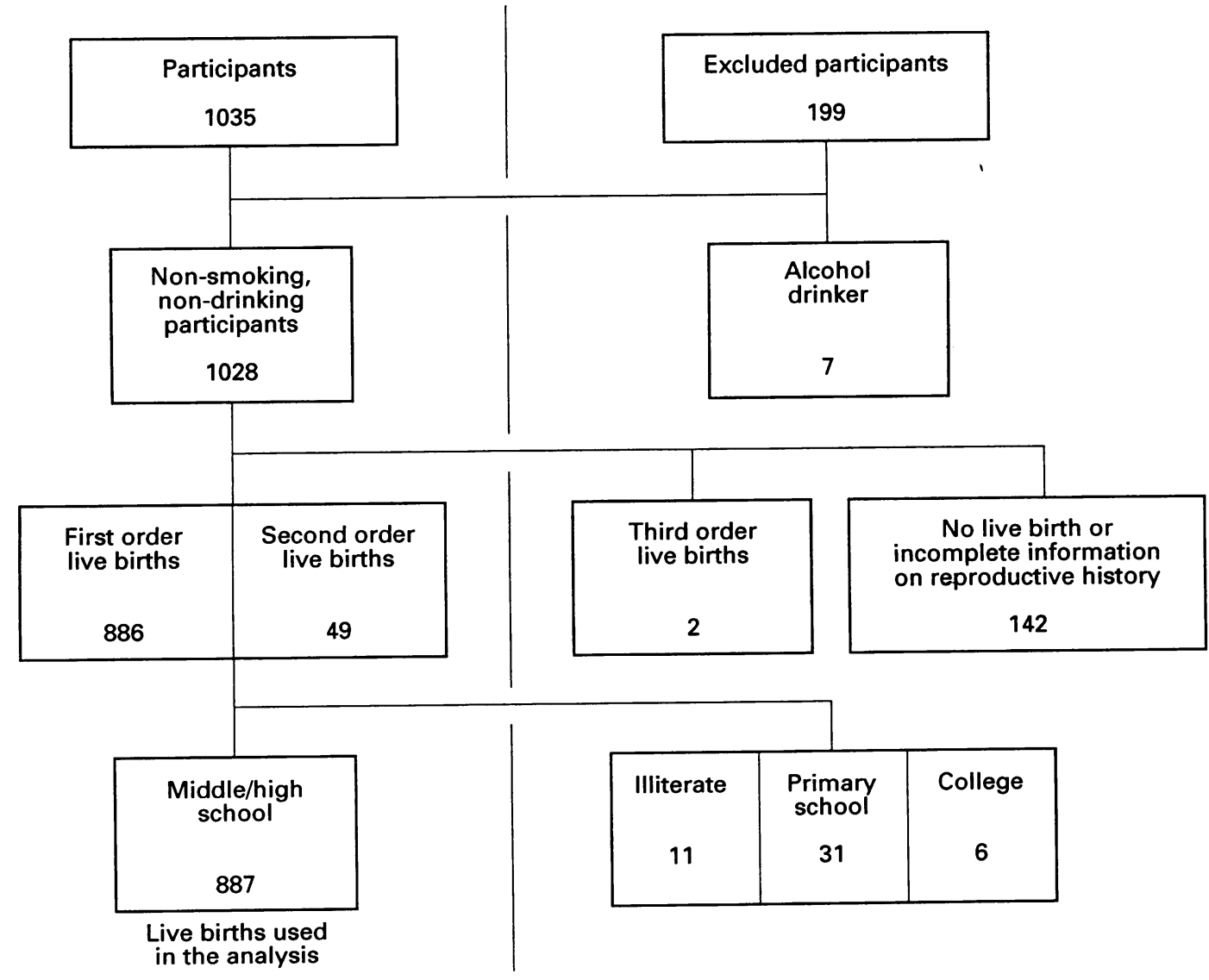


Table 1 Sample characteristics and percentage of rotating shift workers during pregnancy

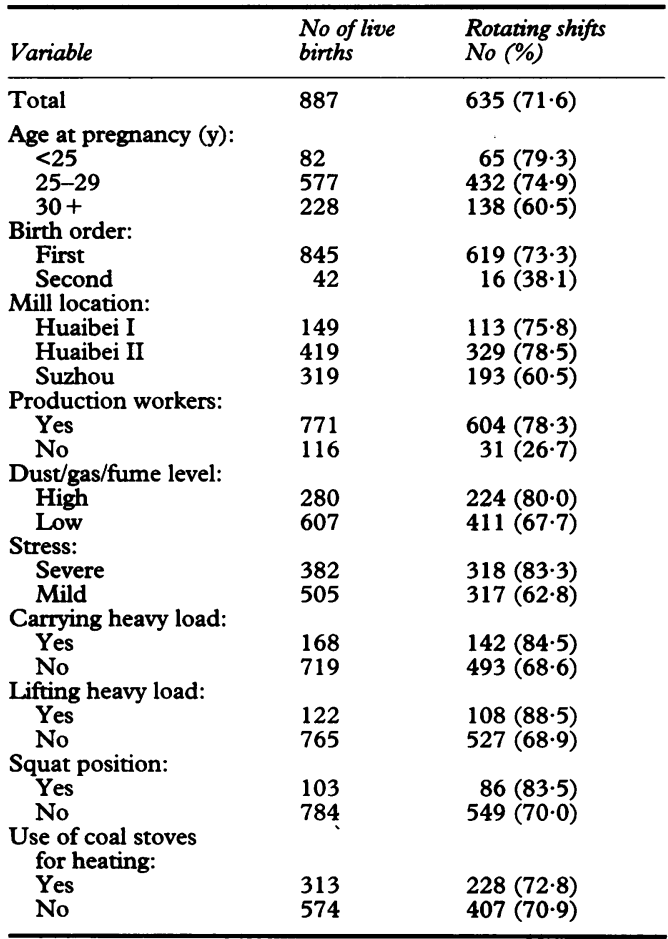

weights were $3248 \mathrm{~g}$ and $3338 \mathrm{~g}$ for rotating shift workers and regular schedule workers respectively. The estimated effect of rotating shiftwork on birth weight was -79 (SE 42) g, which was marginally significant. When gestational age was included in the model, the estimated reduction in birth weight was -63 (SE 42) g. Seventy three per cent of the observations were first order live births. In a separate analysis of the first live births, the estimated effects of rotating shiftwork were statistically significant for both gestational age $(\beta=-0.36$, SE 0.18 weeks) and birth weight $(\beta=-90$, SE $43 \mathrm{~g})$. Seventy eight per cent of women in this study were production workers. The estimated reduction in gestational age associated with rotating shiftwork in the production workers was 0.47 (SE 0.23) weeks, which was comparable with that estimated for the entire sample. The effect on birthweight was - 106 (SE 45) g, 34\% greater than that for the total sample (table 2). A similar result was obtained when the analysis was restricted to the first live births in production workers (table 2).

Binary variables indicating preterm birth ( $<37$ weeks) and low birth weight $(\leqslant 2500 \mathrm{~g})$ were also examined. The incidence of preterm birth was $20 \cdot 0 \%$ and $15 \cdot 1 \%$, respectively, in workers with and without a history of rotating shiftwork during their pregnancy. The incidence of low birth weight in workers reporting shiftwork $(9.3 \%)$ was also greater than that in workers reporting no shiftwork (5.6\%). From a logistic regression model, the adjusted odds ratio of rotating shiftwork was 2.0 (95\% CI $1 \cdot 1-3 \cdot 4)$ for preterm birth and $2 \cdot 1(95 \% \mathrm{CI}$ $1 \cdot 1-4 \cdot 1$ ) for low birth weight (table 3 ). A

Table 2 Means (SD) of gestational age and birth weight and linear regression estimates * for rotating shiftwork

\begin{tabular}{|c|c|c|c|c|c|c|}
\hline \multirow{2}{*}{$\begin{array}{l}\text { Rotating } \\
\text { shiftwork }\end{array}$} & \multicolumn{3}{|c|}{ Gestational age (weeks) } & \multicolumn{3}{|c|}{ Birth weight $(g)$} \\
\hline & Mean $(S D)$ & $S E$ & p Value & Mean (SD) & $S E$ & $p$ Value \\
\hline \multicolumn{7}{|c|}{ All live births ( $n=887)$} \\
\hline $\begin{array}{l}\text { No }(n=252) \\
\text { Yes }(n=635)\end{array}$ & $\begin{array}{l}39 \cdot 0(2 \cdot 0) \\
38 \cdot 8(2 \cdot 5)\end{array}$ & $\begin{array}{l}\text { Reference group } \\
-0.44 \quad 0.20\end{array}$ & 0.03 & $\begin{array}{l}3338(490) \\
3248(488)\end{array}$ & $\begin{array}{l}\text { Reference group } \\
-79\end{array}$ & 0.06 \\
\hline \multicolumn{7}{|c|}{ Production workers only ( $n=771$ ) } \\
\hline Yes $(n=604)$ & $38 \cdot 7(2 \cdot 5)$ & $\begin{array}{ll}-0.47 & 0.23\end{array}$ & 0.04 & $3243(488)$ & $-106 \quad 45$ & 0.02 \\
\hline \multicolumn{7}{|c|}{ First live births only $(n=845)$} \\
\hline $\begin{array}{l}\text { No }(n=226) \\
\text { Yes }(n=619)\end{array}$ & $\begin{array}{l}39 \cdot 1(2 \cdot 0) \\
38 \cdot 8(2 \cdot 4)\end{array}$ & $\begin{array}{lc}\text { Reference group } \\
-0.36 & 0.18\end{array}$ & 0.05 & $\begin{array}{l}3341(490) \\
3248(485)\end{array}$ & $\begin{array}{l}\text { Reference group } \\
-90 \quad 43\end{array}$ & 0.04 \\
\hline $\begin{array}{l}\text { No }(n=150) \\
\text { Yes }(n=589)\end{array}$ & $\begin{array}{l}39.0(1.8) \\
38.8(2.4)\end{array}$ & $\begin{array}{rr} & \text { Production } \\
\text { Reference } & \text { group } \\
-0.39 & 0.20\end{array}$ & $\begin{array}{l}\text { rs and firs } \\
0.06\end{array}$ & $\begin{array}{l}s(n=739) \\
3358(482) \\
3244(485)\end{array}$ & $\begin{array}{l}\text { Reference group } \\
-117 \quad 46\end{array}$ & 0.01 \\
\hline
\end{tabular}

^Adjusted for maternal age at pregnancy, order of live birth, mill location, job title, occupational exposure to dusts/gases/fumes stress, carrying and lifting of heavy loads, working in a squat position, time and duration of leave from the job since pregnancy, and indoor coal combustion for heating.

Table 3 Prevalence (\%) of preterm births and low birthweight and estimated odds ratios (ORs) * for rotating shiftwork

\begin{tabular}{|c|c|c|c|c|c|c|c|c|}
\hline \multirow{2}{*}{$\begin{array}{l}\text { Rotating } \\
\text { shiftwork }\end{array}$} & \multicolumn{4}{|c|}{ Preterm births ( $<37$ weeks) } & \multicolumn{4}{|c|}{ Low birthweight $(\leqslant 2500 \mathrm{~g})$} \\
\hline & No (\%) & $O R$ & $(95 \% C I)$ & p Value & No (\%) & $O R$ & $(95 \% C I)$ & p Value \\
\hline \multicolumn{9}{|c|}{ All live births $(n=887)$} \\
\hline No & $38(15 \cdot 1)$ & $1 \cdot 0$ & - & - & $14(5.6)$ & 1.0 & - & - \\
\hline Yes & $127(20 \cdot 0)$ & $2 \cdot 0$ & $1 \cdot 1-3 \cdot 4$ & 0.02 & $59(9 \cdot 3)$ & $2 \cdot 1$ & $1 \cdot 1-4 \cdot 1$ & 0.03 \\
\hline \multicolumn{9}{|c|}{ Production workers only $(n=771)$} \\
\hline $\begin{array}{l}\text { No } \\
\text { Yes }\end{array}$ & $26(15 \cdot 6)$ & $1 \cdot 0$ & - & - & $12(7 \cdot 2)$ & $1 \cdot 0$ & - & - \\
\hline Yes & $122(20 \cdot 2)$ & 1.9 & $1 \cdot 0-3 \cdot 6$ & 0.04 & $56(9 \cdot 3)$ & 1.9 & $1 \cdot 0-3 \cdot 7$ & 0.06 \\
\hline \multicolumn{9}{|c|}{ First live births only $(n=845)$} \\
\hline No & $33(14 \cdot 6)$ & $1 \cdot 0$ & - & - & $10(4 \cdot 4)$ & $1 \cdot 0$ & - & - \\
\hline Yes & $123(19 \cdot 9)$ & $1 \cdot 8$ & $1 \cdot 0-3 \cdot 1$ & 0.04 & $57(9 \cdot 2)$ & $2 \cdot 5$ & $1 \cdot 2-5 \cdot 4$ & 0.02 \\
\hline \multicolumn{9}{|c|}{ Production workers and first live births ( $n=739$ ) } \\
\hline $\begin{array}{l}\text { No } \\
\text { Yes }\end{array}$ & $24(16 \cdot 0)$ & $1 \cdot 0$ & - & - & $8(5.3)$ & $1 \cdot 0$ & - & - \\
\hline Yes & $118(20 \cdot 0)$ & 1.7 & $1 \cdot 0-3 \cdot 1$ & 0.07 & $54(9.2)$ & $2 \cdot 3$ & $1 \cdot 1-5 \cdot 0$ & 0.03 \\
\hline
\end{tabular}

*Calculated from logistic model adjusting for maternal age at pregnancy, order of live birth, mill location, job title, occupational exposure to dusts/gases/fumes, stress, carrying and lifting of heavy loads, working in a squat position, time and duration of leave from the job since pregnancy, and indoor coal combustion for heating. 
similar result was obtained when the analysis was performed among production workers and first order live births (table 3).

\section{Discussion}

Our study shows a relation between rotating shiftwork and low birth weight and preterm birth in women textile workers. The study has several strengths. Firstly, the study population was homogeneous - that is, the workers were all non-smokers and non-alcohol drinkers and had a similar educational level. Most of the women only had one live birth. Thus potential confounding of these factors in the analyses was minimised. Secondly, all the participants were young (mean age 28.7), and currently employed in the textile mills. Therefore, the bias introduced by retirement (or a survivor effect) should be minimal. Finally, detailed information on rotating shiftwork and other potential occupational risk factors (for example, workplace air pollution, physical activity and position while working) was simultaneously collected in the working environment. We believe that this workforce based epidemiological study offers a more accurate assessment of rotating workshifts (two day rotation with eight day cycle) and other occupational exposures with less measurement error and misclassification than hospital or community based studies. ${ }^{8}$ Also, other important confounders such as indoor air pollution from the use of a coal stove for home heating were also considered in this study.

Circadian rhythms in humans are a mixture of endogenous and exogenous components that are derived from the body's clock and the interaction between the environment and lifestyle. ${ }^{9}$ Numerous human biological variables including body temperature, the sleep-wake cycle, cardiovascular variables, psychomotor performance, endocrine and metabolic factors, responsiveness to various medications, and psychological variables of mood and anxiety follow a 24 hour rhythm under normal nychthemeral conditions. The disruption of biological rhythms is associated with various symptoms, both physical and emotional. ${ }^{10}$ Few studies, however, actually document objectively the adverse health effects of shiftwork. Gastrointestinal disorders have been shown to be associated with shiftwork. ${ }^{11} 12$ The association between cardiovascular disease and shiftwork is less certain, although evidence is mounting. ${ }^{11} 13$

Several recent studies have suggested that shiftwork was associated with low birth weight or preterm birth. ${ }^{45}$ Mamelle and coworkers studied 3437 French women who gave birth at two hospitals. ${ }^{4}$ Association of shiftwork (shiftwork and night work) with preterm births was examined among 1928 working women. The risk ratio was 1.6 and was statistically significant. McDonald and colleagues studied 22761 live births in Montreal to assess maternal occupational risk factors for low birth weight and preterm birth in six main industrial sectors. ${ }^{5}$ Shiftwork (rotating or irregular changing) was found to be signifi- cantly associated with an increased risk of preterm birth in sector 3 (risk ratio 1.9 ), and with low birth weight in sector 2 (risk ratio 1.6). Our estimates for preterm birth and low birth weight are comparable with these results, despite the fact that the previous studies included cigarette smokers, who are known to be at risk for preterm birth and low birth weight.

Few data are available from workforce based studies on rotating shiftwork and pregnancy outcome. Axelsson and colleagues examined the effect of irregular and inconvenient working hours on pregnancy outcome among 654 women employed in a hospital in Sweden between 1980 and $1984 .{ }^{14} \mathrm{~A}$ slight, but not significantly, increased risk of miscarriage was found in women who worked irregular hours or rotating shifts compared with women who worked only during the day (risk ratio $=1.44,95 \%$ CI $0.83-2.51$ ). When the data were analysed separately for smokers and non-smokers, however, infants of non-smoking women who worked irregular hours had significantly lower birth weights than infants of non-smoking women who worked only during the day. At birth order 2 or higher, evening work or rotating shiftwork was also significantly associated with reduced birth weight. Important confounding factors including age at pregnancy, job title, and maternal education were not adjusted in the analysis.

Our study is limited by its retrospective nature, which may introduce selection bias. If some women with a history of rotating shiftwork left or changed jobs before pregnancy or some women with a history of adverse pregnancy outcomes left or switched jobs, the association of low birth weight and preterm births presented in this report may have been underestimated. Because occupational history was self reported, the misclassification of exposure is possible. The net effect of such misclassification is to bias the results towards the null. Such misclassification is unlikely to occur, however, for rotating shiftwork, because this is an objective measurement and the participants had no knowledge about the potential adverse effects of shiftwork on pregnancy outcome.

In summary, the present study showed a significant association of rotating shiftwork with low birth weight and preterm birth in a sample of never smoking women textile workers.

The study was supported in part by grants No R01OH02421 from NIOSH and ESO0002 from NIEHS.

1 Colligan MJ. Methodological and practical issues related to shiftwork research. The 24-hour workday: proceedings of a symposium on variations in work-sleep schedules. Cincinnati, Ohio: Division of Biomedical and Behavioral Science, NIOSH, US Department of Health and Human Services, DHHS (NIOSH) publ No 81-127. 1981;261-7.

2 Ong CN, Kogi K. Shiftwork in developing countries: current issues and trends. In: Scott AJ, eds. Occupational medicine: state of the art reviews. Shiftwork. Philadelphia: Hanley and Belfus Inc, 1990;5:417-28.

3 Wang X, Strobino DM, Guyer B. Differences in causespecific infant mortality among Chinese, Japanese and White Americans. Am f Epidemiol 1992;135:1382-93.

4 Mamelle N, Laumon B, Lazar P. Prematurity and occupational activity during pregnancy. Am $\mathcal{F}$ Epidemiol 1984; 119:309-22. 
5 McDonald $\mathrm{AD}$, McDonald JC, Armstrong $\mathrm{B}$, et al. Prematurity and work in pregnan. $\mathrm{Br} F$ Ind $\mathrm{Med} 1988$ 45:56-62.

6 Pope CA, Xu X. Passive cigarette smoking, coal heating, and respiratory symptoms of nonsmoking women in China. Environ Health Perspect 1993;101:314-6.

7 Liang K-Y, Zeger SL. Longitudinal data analysis using generalized linear models. Biometrika 1986;73:13-22.

$8 \mathrm{Xu} \mathrm{X}$, Christiani DC, Dockery DW, Wang LH, et al Exposure-response relationships between occupationa exposures and chronic respiratory illness. Am Rev Respir Dis 1986;146:413-8.

9 Minors DS, Waterhouse JM. Circadian rhythms in general. In: Scott AJ, ed. Occupational medicine: state of the art reviews. Shiftwork. Philadelphia: Hanley and Belfus Inc, 1990;5:165-82.

10 Scott AJ, Ladou J. Shiftwork: effects on sleep and health with recommendations for medical surveillance and screening. In: Scott AJ, ed. Occupational medicine: state of the art reviews. Shiftwork. Philadelphia: Hanley and Belfus Inc, 1990;5:273-99.

11 Angersbach D, Knauth P, Loskant H, et al. A retrospective cohort study comparing complaints and diseases in day and shift workers. Arch Occup Environ Health 1980:45. 127-40.

12 Minors DS, Scott AR, Waterhouse JM. Circadian arrhythmia: shiftwork, travel and health. $\mathcal{f}$ Occup Med 1986; 36:39-44.

13 Knutsson A, Akerstedt T, Jonsson BG, Orth-Gomer K. Increased risk of ischaemic heart disease in shiftworkers. Lancet 1986;12:89-92.

14 Axelsson G, Rylander R, Molin I. Outcome of pregnancy in relation to irregular and inconvenient work schedules. Br f Ind Med 1989;46:393-8.

\section{Vancouver style}

All manuscripts submitted to Occup Environ Med should conform to the uniform requirements for manuscripts submitted to biomedical journals (known as the Vancouver style.)

Occup Environ Med, together with many other international biomedical journals, has agreed to accept articles prepared in accordance with the Vancouver style. The style (described in full in the BMF, 24 February 1979, p 532) is intended to standardise requirements for authors.

References should be numbered consecutively in the order in which they are first mentioned in the text by Arabic numerals above the line on each occasion the reference is cited (Manson ${ }^{1}$ confirmed other reports $^{2-5} \ldots$. .). In future references to papers submitted to Occup Environ Med should include: the names of all authors if there are seven or less or, if there are more, the first six followed by et al; the title of journal articles or book chapters; the titles of journals abbreviated according to the style of Index Medicus; and the first and final page numbers of the article or chapter. Titles not in Index Medicus should be given in full.

Examples of common forms of references are:

1 International Steering Committee of Medical Editors, Uniform requirements for manuscripts submitted to biomedical journals. $\operatorname{Br}$ Med $\Im$ 1979;1:532-5.

2 Soter NA, Wasserman SI, Austen KF. Cold urticaria: release into the circulation of histamine and eosinophil chemotactic factor of anaphylaxis during cold challenge. N Engl f Med 1976;294:687-90.

3 Weinstein L, Swartz MN. Pathogenic properties of invading micro-organisms. In: Sodeman WA Jr, Sodeman WA, eds. Pathologic physiology, mechanism of disease. Philadelphia: W B Saunders, 1974:457-72. 